\title{
ERRATUM
}

In the manuscript "The play and social constitution of children in a context of early childhood education", DOI: 10.1590/s1413-24782019240063, published in the Rev. Bras. Educ. 2019; v. 24, e240063. Epub Dec 05, 2019:

\section{PAGE 1:}

\section{Where it reads:}

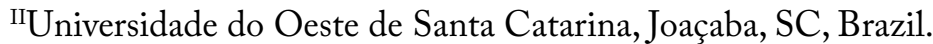

It should read:

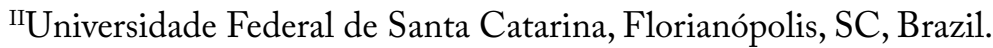

PAGE 2, RESUMO:

\section{Where it reads:}

Este artigo apresenta uma pesquisa sobre o brincar e a constituição social das crianças no campo de educação infantil, no que tange a contextos familiares.

\section{It should read:}

Este artigo apresenta uma pesquisa sobre o brincar e a constituição social das crianças no campo de educação infantil em relação com contextos familiares.

\section{PAGE 23:}

\section{Where it reads:}

Eloísa Acires Candal Rocha has a doctorate in education from the Universidade Estadual de Campinas (UNICAMP). She is a retired professor at the Universidade do Oeste de Santa Catarina (UNOESC).

\section{It should read:}

Eloísa Acires Candal Rocha has a doctorate in education from the Universidade Estadual de Campinas (UNICAMP). She is a retired professor at the Universidade Federal de Santa Catarina (UFSC). 